\title{
Prosthetic management of palatal perforation in heroin abuse patient
}

\author{
Hussein El Charkawi* and Hossam Nasar \\ Prosthodontics Department, Faculty of Oral and Dental Medicine, Future University, Cairo-Egypt
}

\begin{abstract}
Heroin induced palatal perforation is a very infrequent complication. The authors report in this study a patient who suffered palatal perforation as a result of long time of snorting Heroin. He presented complaining of liquid passage from the oral cavity into the nasal cavities and hypernasality during speech. An immediate transparent acrylic partial obturator was constructed and fitted. It was successful in sealing the defect. However after 4 months an enlargement in the perforation was evident due to failure to cease the habit from the patient. It required the fabrication of new palatal obturator to seal the enlarged perforation and enhance the speech. This report discusses the possible lines of treatment of such complication. The report pointed out the possible prosthetic options. It also, emphasizes the importance of a multidisciplinary approach in management of drug abuse patients and complications encountered in their treatment. The use of palatal obturators improves patient quality of life, avoiding socially embarrassing situations such as the passage of fluids and solids into the nasal passages and maxillary sinuses, or a nasal tone.
\end{abstract}

\section{Introduction}

Heroin (diacetylmorphine) is a highly addictive Schedule I drug, and a heavily abused and extremely potent opiate. It is processed from morphine; a naturally-occurring substance extracted from the opium poppy (Papaver Somniferum) a plant indigenous to the Middle East and Southeast Asia. Pure heroin, which is a bitter-tasting white powder, is rarely sold on the streets. Most that is sold is a powder varying in color from white to dark brown. The differences in color are due to impurities in the manufacturing process and/or the presence of other drugs or additives such as powdered milk or quinine [1].

Heroin induced palatal perforation is a very infrequent complication. Like other opiates, heroin use blocks the brain's ability to perceive pain. Heroin abusers, particularly those with prior history of drug abuse, may initially be able to conceal signs and symptoms of their heroin use. No epidemiological characteristics of this disorder relating to patient age or gender have been established $[2,3]$. The diagnosis of this complication requires a detailed clinical history, including antecedents of Heroin abuse. Evaluation of the clinical and radiological studies is also required in order to identify palatal bone erosion and perforation of the soft or hard palate [4,5]. The management approach is subject to controversy. The lack of will to abandon the habit, or the usual patient inefficacy in achieving complete rehabilitation, causes specialists to adopt a more conservative treatment approach, in many cases without proposing surgical sealing of the defect. The use of palatal obturators improves patient quality of life, avoiding socially embarrassing situations such as the passage of fluids and solids into the nasal passages and maxillary sinuses, or a nasal tone [6-9].

Peyrière et al. reported the complications in 24 patients. The other complications reported with heroin snorting were nasal perforation (11 cases), nasal ulceration or erythema (5 cases), nasal septum necrosis (5 cases), pharyngeal ulceration ( 3 cases), and palate damages (5 cases). The most common clinical signs and symptoms were nasal pain, purulent sputum, dysphagia, and rhinitis [10].

\section{Case report}

A 33-years old Caucasian male who works as a jewelry craftsman presented complaining of liquid passage from the oral cavity into the nasal cavities and hypernasality during speech. He also, complained of severe xerostomia that sometimes make swallowing difficult. His weight is 40 kilos and height $160 \mathrm{~cm}$. He looks very pale, week with projecting maxillary bones (Figure 1). Exploration revealed a painless

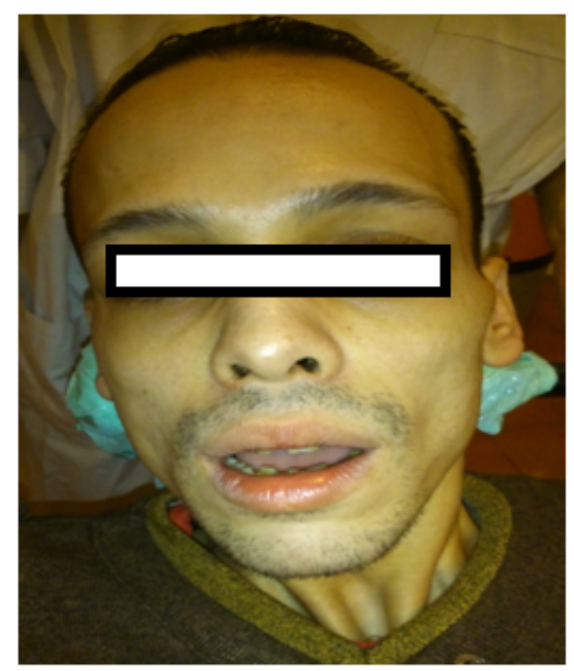

Figure 1. The patient pale face.

Correspondence to: Hussein El Charkawi, 2 D Road 199 Degla, Maadi, 11347, Cairo, Egypt, Tel: 01222150439; E-mail: helcharkawi@gmail.com

Key words: heroin, obturators, oronasal communication, palatal perforation

Received: July 02, 2015; Accepted: August 19, 2015; Published: August 24, 2015 
round oronasal lesion measuring $0.5 \mathrm{~cm}$ in greater diameter, located in the posterior portion of the hard palate, with no signs of inflammation or suppuration. Computed tomography revealed the absence of proprietary structures of the nasal cavities (Figure 2 and 3). Further questioning confirmed a history of nasal heroin snorting which the patient openly admitted. He mentioned that he used to inhale about 10 grams per day for the last ten years. He had stopped once heroin abuse for one year, but then he returned back again for the last five years. He indicated that his daily use is reduced to be from 0.5 to 1 gram per day. He also admitted to smoking 30-50 cigarettes per day but did not drink alcohol. The patient described that the stuff's color he uses range from white to brown and comes in a chalky sticks that he has to crush before snorting using a straw. He also, indicated that he always mix his stuff with some pills like Tramadol (pain killer).

Being a jewelry maker, he made a lot of silver wear that require sand blasting and polishing which produces very fine silver dust that goes directly to his nose despite wearing a mask.

The patient's erythrocyte sedimentation rate was normal and the

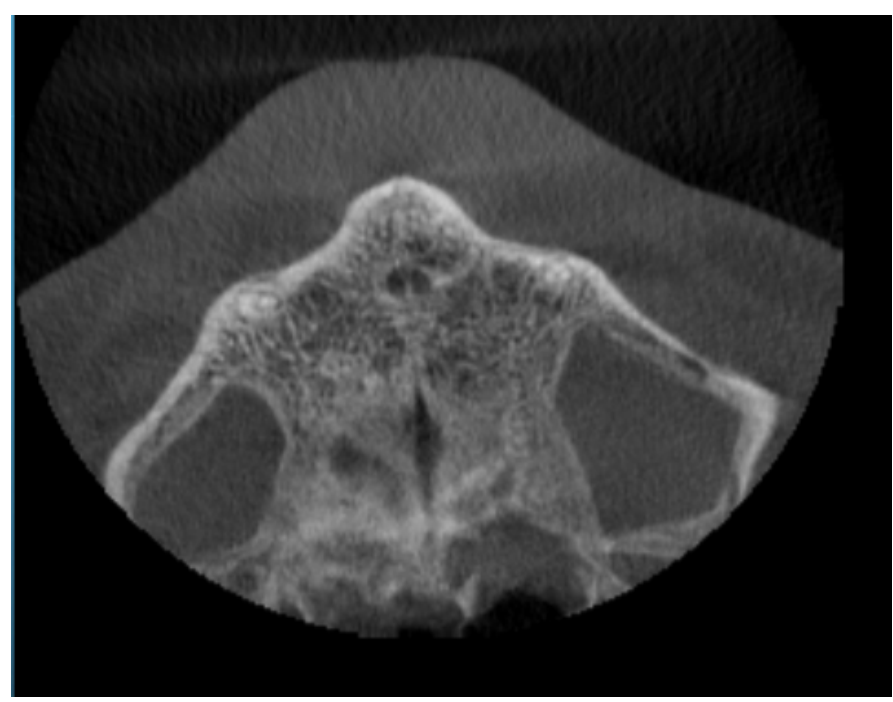

Figure 2. CBCT horizontal section showing perforation of the palate.

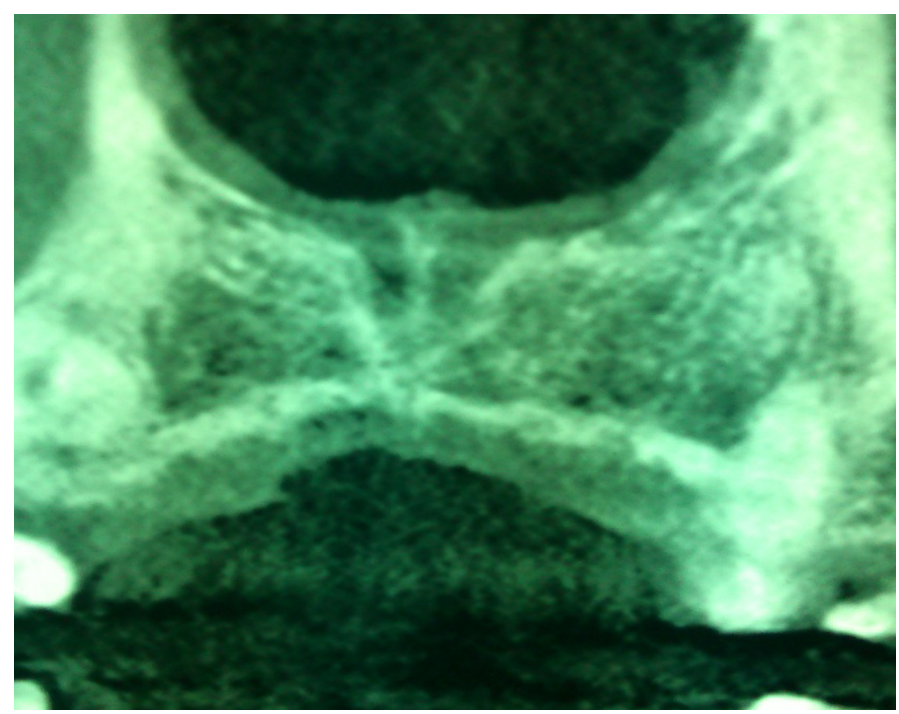

Figure 3. $\mathrm{CBCT}$ coronal section showing the connection between the oral and nasal cavities.

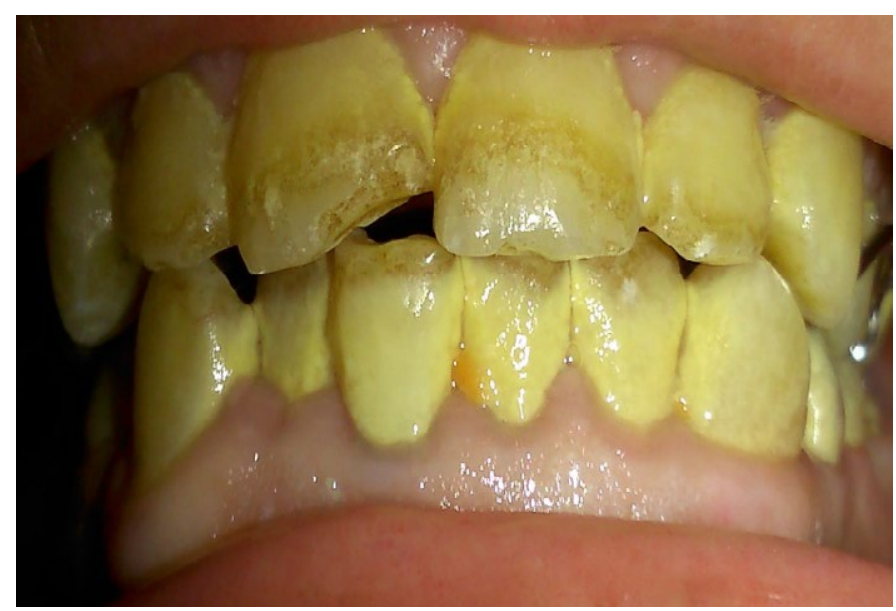

Figure 4. Gingival recession, necrosis, yellowish discoloration and erosion of enamel.

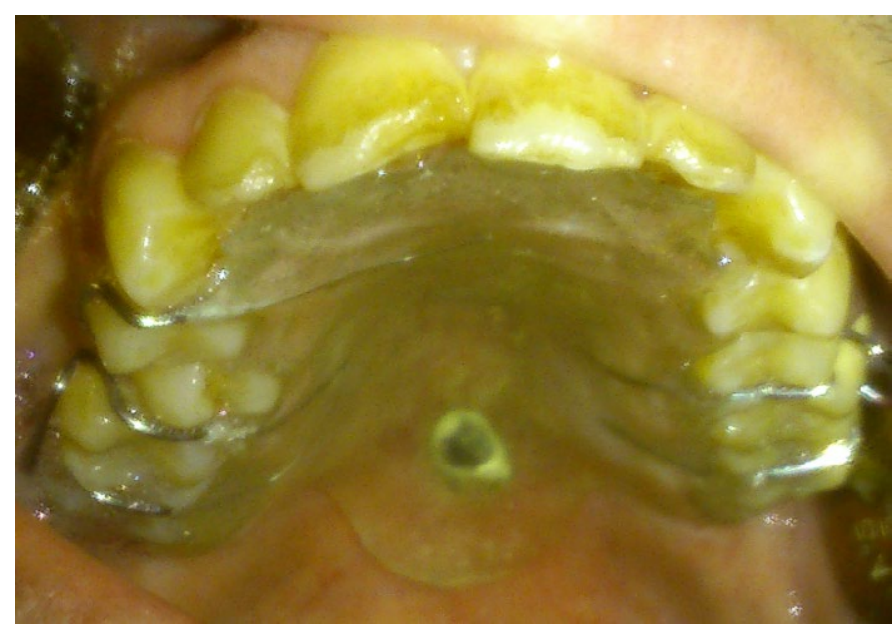

Figure 5. First prosthetic obturators seal the palatal perforation (note the size of perforation.

following tests produced no pathological results: complete blood count, liver and renal function tests, serology for syphilis, bacteriological cultures including stains for fungi and tuberculosis, chest radiograph, extensive urine analysis, examination of rheumatoid factors as well as antinuclear and antimitochondrial tests.

Examination confirmed the presence of a small round perforation, measuring 4-5 $\mathrm{mm}$, in the center of the posterior hard palate. Intra oral examination reveals also, gingival recession, ulceration, yellowish discoloration of the teeth and necrosis (Figure 4). Erosion of enamel/ dentine and some corrosion of metal restorations were noticed. An immediate transparent acrylic partial obturator was constructed and fitted which was successful in sealing the defect (Figure 5). The patient was advised that at this stage it was unwise to attempt any surgical repair, as this was most likely to fail, but that it could become a viable option once the heroin abuse ceased. He was informed of the risk of further enlargement of the defect and regular review visits were recommended. He failed to return for any of these appointments. However, after 4 months, the patient showed again complaining that his obturator was not sealed anymore and fluids start to come from his nose again. On examination, it was found that the palatal perforation became ovoid in shape and enlarged to be 5-10 mm (Figure 6). A new acrylic obturator was constructed to seal the defect and improve the nasal tone. 


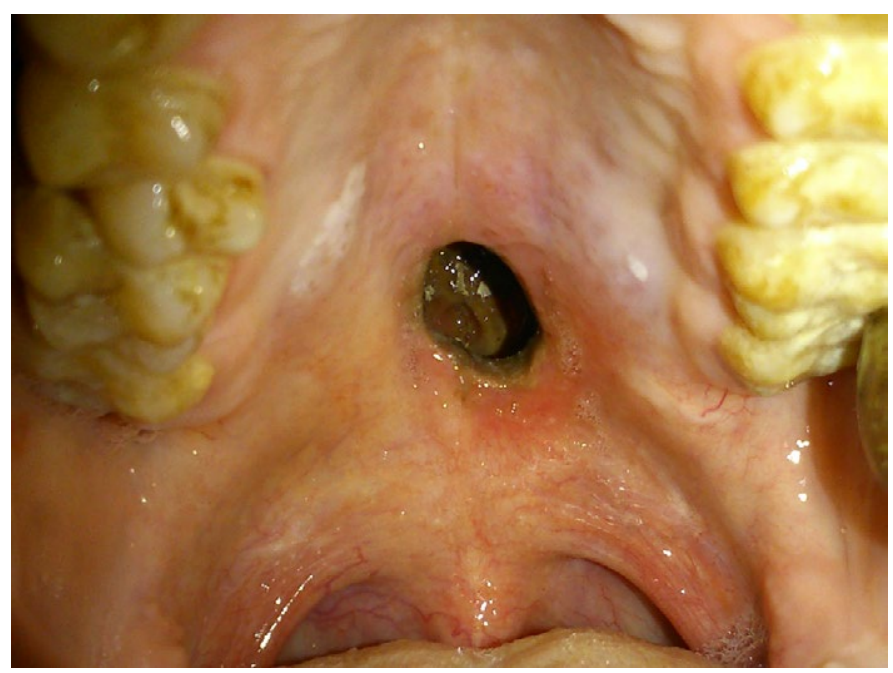

Figure 6. Enlarged perforation after 4 months.

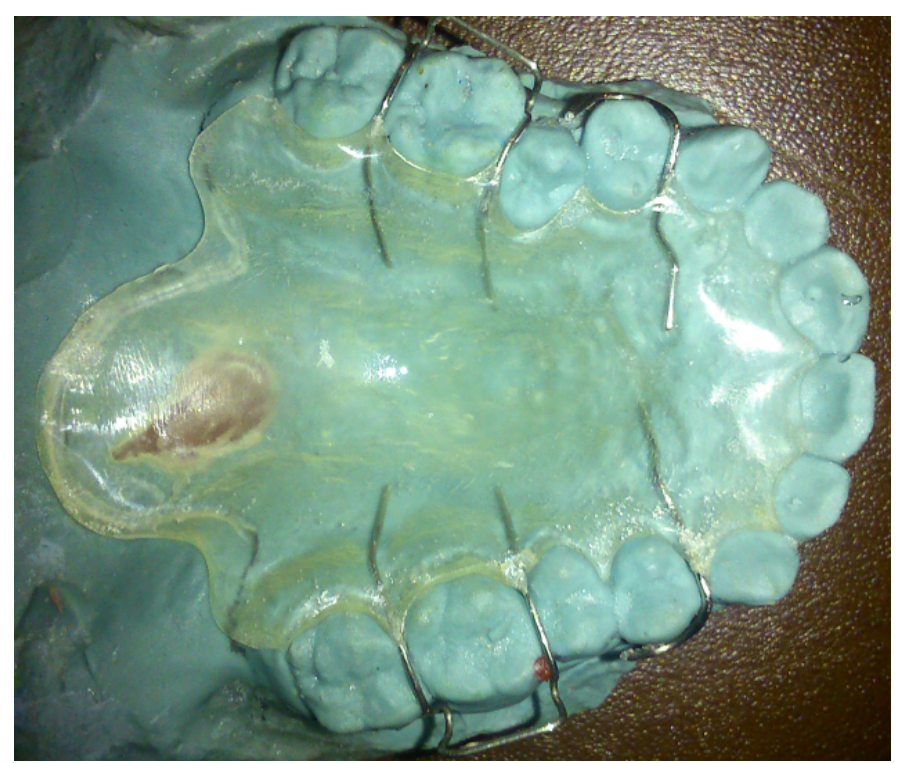

Figure 7. Prosthetic obturator on the cast showing the posterior extension and retentive clasps.

The prosthetic procedures started with blocking the perforation with $2 \times 2 \mathrm{~cm}$ lubricated gauze with Vaseline to prevent entrapment of the impression material inside the defect. A stock tray that is posteriorly extended with pink wax to cover the area distal to the perforation was used. This extension was made to end the posterior border of the obturator on the junction between the movable and immovable parts of the soft palate. The tray was loaded with irreversible hydrocolloid material and seated from posterior to anterior direction.

On the poured cast, a clear acrylic plate was fabricated to detect any pressure areas during insertion. The perforation was blocked in the cast by wax to prevent unwanted extension inside the defect that may increase the weight of the prosthesis. Extra care was made to just seal the opening without inducing pressure on the surrounding tissue. The retention elements were provided via Adams cribs and wrought wire clasps on the first molar and first premolar in both sides. Upon insertion, the patient felt immediate improvement in his speech and no fluids entered the nose. Oral hygiene measures and methods of cleaning the obturator were prescribed to the patient (Figure 7 and 8).
Through discussions with the patient to motivate him to cease sniffing and snorting heroin were carried out in successive sessions. Showing the patient the huge enlargement (it almost doubled its size) that occurred in just four months was an assist. It was pointed-out that enlargement of the perforation could be a life-threatening to the patient himself as it may lead to inability to eat or speck. Further enlargement may complicate fabrication of future obturators. Also, showing the patient some before and after treatment photos raised hopes that he may still have a chance and it is not the end of the world. The authors advised the patient to cease this attitude immediately as this obturator will be the only life saving measure that all medical specialties could provide. It was pointed out to the patient that according to literature, surgical repair of the perforation could only be carried out in patients who will be able to stop this heroin abuse and addiction for at least one year before the surgery could be suggested.

\section{Discussion}

Palatal perforation resulting from insufflation of cocaine has been well documented. In comparison, reports of destructive orofacial lesions resulting from intranasal abuse of prescription narcotics are rare [11]. This study presents the clinical findings and prosthetic management in a case of palatal perforation arising in a patient abusing a prescription opioid drug.

Specific management of the palatal defect may be to do nothing, to seal the defect or to repair the defect. Obturators are a successful method of managing the speech and masticatory problems. Surgery is another option but extensive scarring in these lesions makes any attempt at palatal repair hazardous. In cocaine and heroin abusers surgical intervention should be delayed for at least one year following confirmation of drug cessation and lesion stability $[12,13]$. The patient should remain under review to check for progressive necrosis. Reconstruction is again controversial due to the etiology of tissue damage. Necrosis renders the tissues more likely to breakdown following surgical repair. The better option seems to be the non-surgical conservative approach. There exists a patient population for whom rehabilitation must be approached with the help of a prosthodontist. The function of a prosthodontist is to restore the basic vital functions of mastication, deglutition and speech production. To accomplish this,

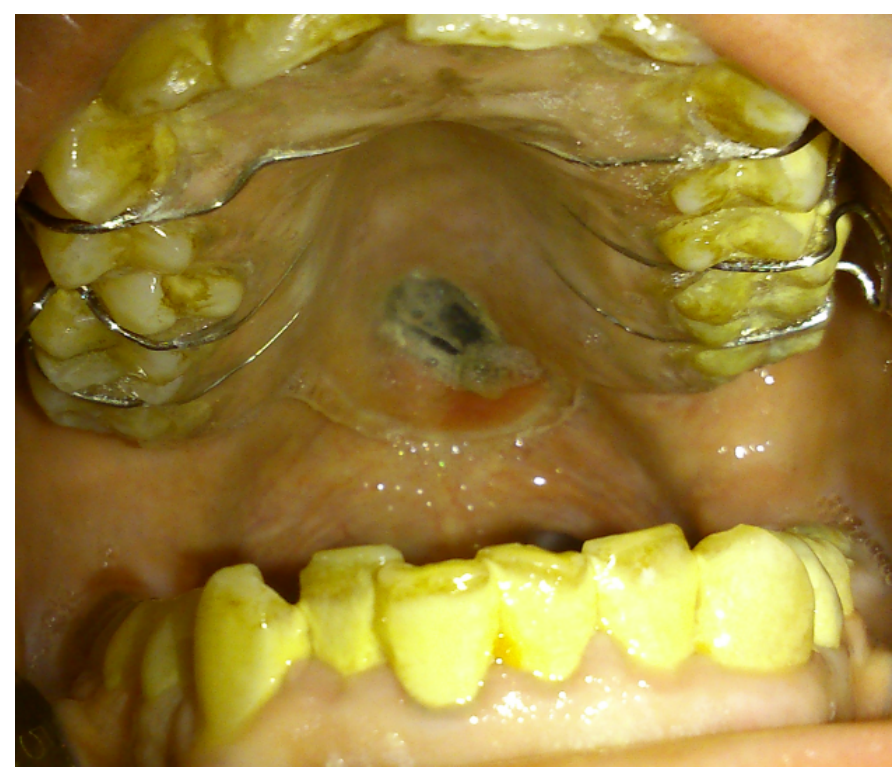

Figure 8. The new obturator in place sealing the perforation. 
the prosthodontist is most concerned with the preservation of residual teeth, the health of the periodontium, and the physiology of residual soft palate musculature and the activity of the anatomic structures identified with the palatopharyngeal sphincters.

The possible cause of perforation in cocaine abuser could be attributed to being, a potent vasoconstrictor, can lead to ischemia, necrosis, and ulceration. However, the mechanisms of tissue damage with opioid abuse remain unknown. One possible explanation for tissue injury with opioid abuse may lie in the effects of opioids on the immune system [14]. Lymphocytes and macrophages are known to possess opioid immunosuppressive effects through the inhibition of cell-mediated immunity, allowing for the development of invasive bacterial or fungal infections in otherwise healthy opioid abusers [1416].

While the possibility of past cocaine use cannot be completely excluded, the potential for opiates or other drugs being mixed with the drug preparation to produce destructive orofacial lesions should be considered [16]. The patient mentioned that he mixes his stuff with other materials and among them Tramadol tablets. Tramadol (marketed as Tramadol in the Middle East) is an opioid pain medication which is used to treat moderate to moderately severe pain. Most users believe that Tramadol can increase their ability to endure heavy works and also-as greatly important- improve their sexual ability and increase intercourse time. However, Tramadol can cause a higher incidence of nausea, dizziness, loss of appetite compared with opiates, which could deter abuse [17].

When repair is indicated, it is the site and size of the defect which dictates the most appropriate type of flap or graft. In most cases palatal defects and the floor of the nose are usually grafted using standard cleft palate surgery techniques [18]. For the palate local flaps are the best option wherever possible [18]. A recent case, of congenital syphilis, reported successful repair of a large palatal defect using a tongue flap. The success was attributed to the excellent vascular supply and the proximity of the donor and recipient sites [16]. Speech therapy was advised as part of the rehabilitation program. Distal flaps may be an option particularly for large defects. Recent evidence suggests promising results are obtainable with the use of microsurgical forearm flaps $[18,19]$.

Concurrent treatment or use of other CNS depressant drugs such as benzodiazepines, barbiturates, MAO inhibitors, antihistamines, hypnotics, general anesthetics, and tricyclic antidepressants may increase the risk of respiratory depression, hypotension, coma, and profound sedation [20]. Titration of anesthetic agents may be more difficult in these patients as tolerance may develop to the effects of narcotic drugs. Also, hypotension is often seen upon induction of anesthesia [21].

An increase in dental caries has been seen in heroin abusers [19]. This might be the result of their intense craving for sweets [22-26], or due to apparent xerostomia, anxiety regarding dental treatment [22], and poor oral hygiene. Also of importance to the dental professional is the increased incidence of periodontal disease, oral fungal infections [27], oral viral infections [28], and hyperpigmentation of the tongue [29]. As the primary oral effect of heroin use is dental decay [26], the dentist must be aware of this and incorporate measures such as more frequent recall appointments and constant reinforcements of oral hygiene with the patient.

Prosthetic obturators avoid nasal reflux, facilitating correct swallowing and sufficient speech performance. The only contraindication to such devices is patient tolerance of the obturator, since in some cases the obturator size required to fully seal the defect can cause nausea [30].

Another temporary option that is available is the positioning of a silicone button to close the perforation and, thus, improve the air flow in the nose and reduce progression of local necrosis. Together with the button, the positioning is described, under local anesthesia, of two layers per septal side of hyaluronic acid, at different levels of esterification, kept in site by the button as a "sandwich" in order to obtain better re-growth of the mucosa and fewer scabs and bleeding [31].

This type of prostheses is available in various materials (e.g. acrylic, plastic, silicone). The basic design is that of 2 flat disks connected to a central solid hub. In general, placement requires that the septum, anterior and posterior to the perforation, is relatively straight. Sometimes, a simple surgery (septoplasty) may be necessary to straighten the septum surrounding the perforation before the prosthesis is placed. Insertion is not always easy. New devices have been made with flexible disks and hubs to improve accommodation of any irregularities of the neighboring septum [32] (Figure 9).

One of the important aspects in management of complications of drug abuse is the psychological aspects. The patient's response noticed in this situation range from complete denial of the problem and link it to the drug addiction, fear of stigma, to impaired insight to accept the consequences. In a Psychological study by Businco et al, they reported lack of compliance of the patients and constantly missing the scheduled follow-up visits resulted in complete therapy being performed in only $15.3 \%$ of the patients in their sample. None of the 11 cocaine patients' abusers who presented nasal septal perforation agreed to stop cocaine abuse despite their awareness of the damage that occurred [30].

\section{Conclusion}

Prosthetic obturators made to seal a palatal perforation that resulted from heroin snorting over a long period of time seem to be the treatment of choice. The use of palatal obturators improves patient quality of life, avoiding socially embarrassing situations such as the passage of fluids and solids into the nasal passages and maxillary sinuses, or a nasal tone. It is very conservative line of treatment that respects the anatomy and physiology of the damaged tissue in this area and eliminates the risk of necrosis that renders the tissues more likely

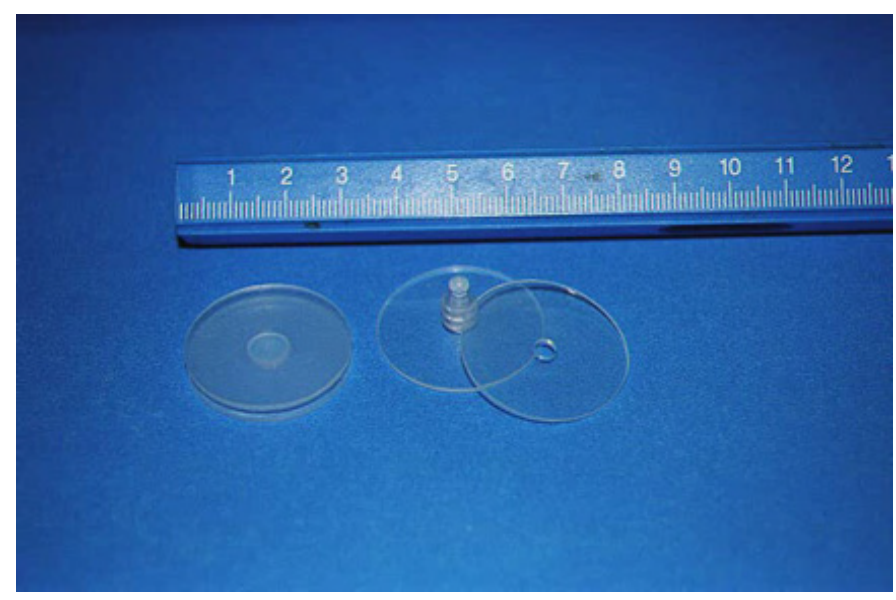

Figure 9. Silicone bottom to close palatal perforation. 
to breakdown following surgical repair. It is easy to fabricate, insert and maintain. The problems of drug abuse in general are complicated medico-social problems that necessitate the collaboration of many specialists in a multidisciplinary approach. One important aspect of the treatment is the proper motivation of the patient to abandon and cease this drug addiction. The patient's own will to stop is crucial to success and hence proper motivation and psychological and social support during cessation period and after are essential.

\section{Conflict of interest}

The authors report no conflicts of interest related to this study.

\section{References}

1. ONDCP HeroinPage. May 30, 2002.

2. Caravaca A, Casas F, Mochón A, De Luna A, San Martín A, et al. (1999) Centrofacial necrosis secondary to cocaine use. Acta Otorrinolaringol Esp 50: 414-416. [Crossref]

3. Padilla-Rosas M, Jimenez-Santos CI, García-González CL (2006) Palatine perforation induced by cocaine. Med Oral Patol Oral Cir Bucal 11: E239-242. [Crossref]

4. Peñarrocha M, Bagán JV, Peñarrocha MA, Silvestre FJ (2000) Cluster headache and cocaine use. Oral Surg Oral Med Oral Pathol Oral Radiol Endod 90: 271-274. [Crossref]

5. Di Cosola M, Turco M, Acero J, Navarro-Vila C, Cortelazzi R (2007) Cocaine-related syndrome and palatal reconstruction: report of a series of cases. Int J Oral Maxillofac Surg 36: 721-727. [Crossref]

6. Genden EM, Wallace DI, Okay D, Urken ML (2004) Reconstruction of the hard palate using the radial forearm free flap: indications and outcomes. Head Neck 26: 808-814. [Crossref]

7. Serrano-Sánchez P, Bagán JV, Jiménez-Soriano Y, Sarrión G (2010) Palatal perforations secondary to inhaled cocaine abuse. Presentation of five cases. J Clin Exp Dent 2: e105-9.

8. Goodger NM, Wang J, Pogrel MA (2005) Palatal and nasal necrosis resulting from cocaine misuse. Br Dent $J$ 198: 333-334. [Crossref]

9. Di Cosola M, Turco M, Acero J, Navarro-Vila C, Cortelazzi R (2007) Cocaine-related syndrome and palatal reconstruction: report of a series of cases. Int J Oral Maxillofac Surg 36: 721-727. [Crossref]

10. Peyrière H, Léglise Y, Rousseau A, Cartier C, Gibaja V, et al. (2013) Necrosis of the intranasal structures and soft palate as a result of heroin snorting: a case series. Subst Abus 34: 409-414. [Crossref]

11. Jewers WM, Rawal YB, Allen CM, Kalmar JR, Fox E, et al. (2005) Palatal perforation associated with intranasal prescription narcotic abuse. Oral Surg Oral Med Oral Pathol Oral Radiol Endod 99: 594-597. [Crossref]

12. Jewers WM, Rawal YB, Allen CM, Kalmar JR, Fox E, et al. (2005) Palatal perforation associated with intranasal prescription narcotic abuse. Oral Surg Oral Med Oral Pathol Oral Radiol Endod 99: 594-597. [Crossref]
13. Lancaster J, Belloso A, Wilson CA, McCormick M (2000) Rare case of naso-ora fistula with extensive osteocartilaginous necrosis secondary to cocaine abuse: review of otorhinolaryngological presentations in cocaine addicts. J Laryngol Otol 114: 630633. [Crossref]

14. Tubaro E, Borelli G, Croce C, Cavallo G, Santiangeli C (1983) Effect of morphine on resistance to infection. $J$ Infect Dis 148: 656-666. [Crossref]

15. Rouveix B1 (1992) Opiates and immune function. Consequences on infectious diseases with special reference to AIDS. Therapie 47: 503-512. [Crossref]

16. Bakhshaee M, Khadivi E, Naseri Sadr M, Esmatinia F (2013) Nasal Septum Perforation due to Methamphetamine abuse. Iran J Otorhinolaryngol 25: 53-56. [Crossref]

17. Tramadol Hydrochloride. The American Society of Health-System Pharmacists. Retrieved Dec, 2014.

18. Monasterio L, Morovic GC (2003) Midline palate perforation from cocaine abuse Plast Reconstr Surg 112: 914-915. [Crossref]

19. Serrano-Sánchez P, Bagán JV, Jiménez-Soriano Y, Sarrión G (2010) Palatal perforations secondary to inhaled cocaine abuse. Presentation of five cases. J Clin Exp Dent 2: e105-9.

20. Marshall DM, Amjad I, Wolfe SA (2003) Use of the radial forearm flap for deep, central, midfacial defects. Plast Reconstr Surg 111: 56-64. [Crossref]

21. National Highway Traffic Safety Administration (2010) Morphine (and heroin)

22. Sandler NA (2001) Patients who abuse drugs. Oral Surg Oral Med Oral Pathol Oral Radiol Endod 91: 12-14. [Crossref]

23. Pillari G, Narus J (1973) Physical effects of heroin addiction. Am J Nurs 73: 2105 2108. [Crossref]

24. Colon PG Jr (1974) The effects of heroin addiction on teeth. J Psychedelic Drugs 6 : $57-60$

25. Rosenstein DI (1975) Effect of long-term addiction to heroin on oral tissues. J Public Health Dent 35: 118-122. [Crossref]

26. Shapiro S, Pollack BR, Gallant D (1970) The oral health of narcotic addicts. J Public Health Dent 30: 244-249. [Crossref]

27. Yahya MD, Watson RR (1987) Immunomodulation by morphine and marijuana. Life Sci 41: 2503-2510. [Crossref]

28. Picozzi A, Dworkin SF, Leeds JG, Nash J (1972) Dental and associated attitudinal aspects of heroin addiction: a pilot study. J Dent Res 51: 869. [Crossref]

29. Westerhof W, Wolters EC, Brookbakker JT, Boelen RE, Schipper ME (1983) Pigmented lesions of the tongue in heroin addicts--fixed drug eruption. $\mathrm{Br}$ J Dermatol 109: 605-610. [Crossref]

30. Businco LD, Lauriello M, Marsico C, Corbisiero A, Cipriani O, et al. (2008) Psychological aspects and treatment of patients with nasal septal perforation due to cocaine inhalation. Acta Otorhinolaryngol Ital 28: 247-251. [Crossref]

31. Blind A, Hulterström A, Berggren D (2009) Treatment of nasal septal perforations with a custom-made prosthesis. Eur Arch Otorhinolaryngol 266: 65-69. [Crossref]

32. Federspil PA, Schneider M(2006) The custom made septal button. Laryngorhinootologie 85: 323-325. [Crossref]

Copyright: (C2015 El Charkawi H. This is an open-access article distributed under the terms of the Creative Commons Attribution License, which permits unrestricted use, distribution, and reproduction in any medium, provided the original author and source are credited. 